\title{
Research Progress on the Biochemical Modification of Titanium Implant Surface
}

\author{
Yingjie Mao and Xiaodong Li ${ }^{*}$ \\ The Affiliated Stomatology Hospital, College of Medicine, Zhejiang University, Hangzhou 310006, People's Republic of China
}

\begin{abstract}
Researchers are in constant search for the ideal implant surface condition in an attempt to improve osseointegration and to increase bone-to-implant contact. Although various techniques such as physicochemical and morphologic modification, have been proposed, they are still incapable of ensuring predictable results and guaranteed success. In recent years, investigators have also attempted to improve bone formation around implants via using biochemical modification. Various kinds of biomolecules have been introduced to endow the titanium surfaces bioactivities because of their certain bone-growth promoting capabilities. A review of the research progress is given in this paper concerning the biochemical modification of the implant surface.
\end{abstract}

Keywords: Implant interface; Titanium; Biochemical modification; Osseointegration

\section{Introduction}

Nowadays, artificial implants, a third denture of human, can maximize the chewing efficiency of patients with missing teeth, delay the absorption of alveolar bone and improve the quality of life. Osseointegration of the interface between the bone and implants, introduced first by Branemark et al. [1,2], is the most determining factor in oral clinical implant applications. As the main material in dental implant, titanium (Ti) and its alloys have been widely used, because of their excellent biophysical properties including high mechanical strength, corrosion resistance, low module of elasticity, and biocompatibility. However, the osseointegration and osteoconductive properties of $\mathrm{Ti}$ based implants are essentially limited. In addition, $\mathrm{Ti}$ based implants encounter specific complications associated with its incorporation and stability at the host interface, because of limited cell adhesion and the implants susceptibility to bacterial infections [3]. Hence, recent researches have been focused on improving surface treatments to promote osseointegration and osteoconductive properties of Ti based implants.

There are several modalities of the Ti based implant surface to promote faster and more effective osseointegration of the bone-toimplant interface. As described by Ito et al. [4], the approaches to modify Ti based implant surfaces can be classified as physicochemical, morphologic or biochemical modification (Figure 1). Conventional physicochemical and morphologic treatments based on surface modifications like plasma spraying [5], alkaline treatment [6], hydroxyapatite coating [7], sandblasting and acid etching [8,9] are established, in order to improve osseointegration in bone healing process. Another promising and investigated strategy is immobilization of biomolecules to $\mathrm{Ti}$ based implant surfaces to create bioactive $\mathrm{Ti}$ surfaces [10]. This biochemical surface modification can provide direct biochemical and biophysical signals, which can regulate and control the assembly and differentiation of cells to create the environment for adsorption of matrix proteins and promote cell-extracellular matrix (ECM) interaction on Ti implants.

Various kinds of bioactive molecules such as collagen, growth factor, peptides and DNA et al. attract wide attentions in implant surface modification owing to their specific bioactive abilities, which have been proven to enhance and/or accelerate the process of osteoblastic function in vitro [11]. As the molecules are integrated into the surface of implants, they are anticipated to have sustained and controlled release profiles at the implantation site [12]. Meanwhile, these biomolecules should have no harm to the hosts. This review will summarize the research progress according to the bioactive substances introduced in the biochemical modification of $\mathrm{Ti}$ implant surface.

\section{Bioactive Substances used for Biochemical Modification of Ti Implants}

\section{ECM}

As successful implant biomaterials, they must support the adhesion, organization, differentiation, and matrix mineralization of osteoblasts and osteoprogenitor cells. Cell fates such as proliferation and differentiation are determined by a complex interplay of signals from the extracellular environment. These signals include (1) insoluble molecules within ECM, (2) soluble and/or matrix-associated biochemicals such as systemic hormones or growth factors and cytokines that act locally, and (3) cell-cell receptors (Figure 2) [13]. The ECM itself contains multiple types of insoluble molecules, forming a meshwork of structural proteins associated to each other. As modified materials, the components of ECM

Implant Surface Modification Techniques

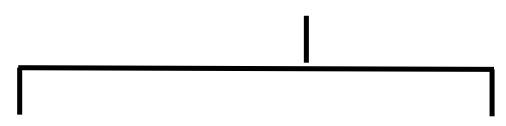

biochemical modification

$$
\begin{gathered}
\text { morphologic modification } \\
\text { plasma spraying, } \\
\text { alkaline treatment } \\
\text { hydroxyapatite coating } \\
\text { sandblasting } \\
\text { acid etching } \\
\text { et al }
\end{gathered}
$$$$
\text { physicochemical and }
$$

$$
\begin{aligned}
& \text { ECM } \\
& \text { collagen } \\
& \text { growth factor } \\
& \text { polypeptide } \\
& \text { DNA } \\
& \text { et al }
\end{aligned}
$$

Figure 1: Implant surface modification techniques.

*Corresponding author: Xiaodong $\mathrm{Li}$, The Affiliated Stomatology Hospital, College of Medicine, Zhejiang University, Hangzhou 310006, People's Republic of China, Tel: 8657188206296; E-mail: cisarli@zju.edu.cn

Received October 04, 2014; Accepted November 10, 2014; Published November 12, 2014

Citation: Mao Y, Li X (2014) Research Progress on the Biochemical Modification of Titanium Implant Surface. Med chem 4: 742-747. doi:10.4172/2161-0444.1000224

Copyright: (c) 2014 Mao Y, et al. This is an open-access article distributed under the terms of the Creative Commons Attribution License, which permits unrestricted use, distribution, and reproduction in any medium, provided the original author and source are credited. 


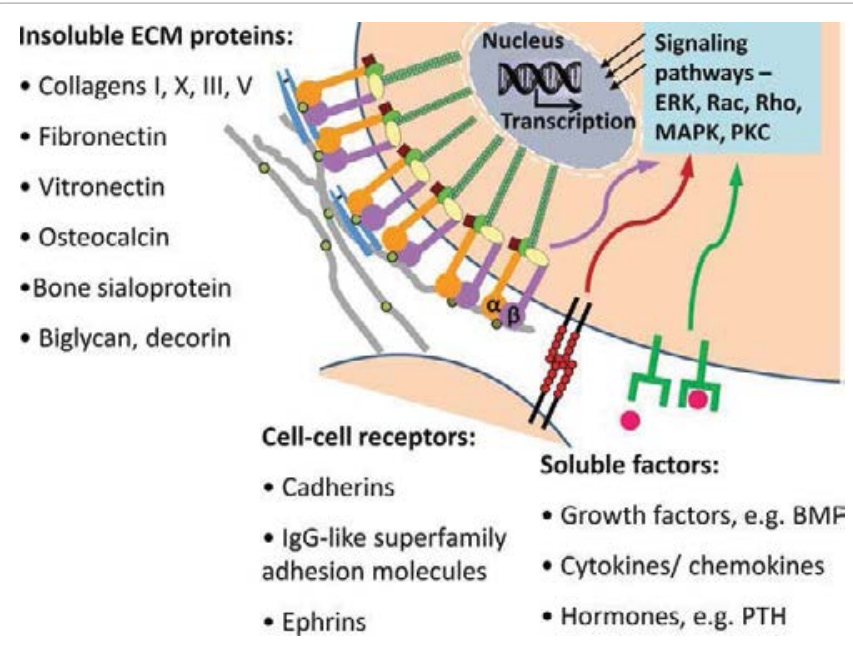

Figure 2: Bioactive signals found within the extracellular environment in bone.

collaborate to complete all kinds of biological activities, which cannot be finished by any molecule alone. Cell-to-ECM contact is mediated by cell adhesion receptors, e.g. integrins, which include specific amino acid sequences, in particular the peptide Arg-Gly-Asp (RGD) sequence. In addition to cell attachment, ECM plays an active role in regulating cellular processes influencing migration, proliferation, morphological change, gene expression and cell survival by intracellular signaling [14]. Additionally, ECM proteoglycans and their glycosaminoglycans, like chondroitin sulfate, are able to bind cytokines and growth factors [15]. Hence, the biological acceptance and function of Ti implants might be improved by modifying their surfaces with ECM components, which has become one of the most important research directions.

Datat et al. [16] investigated the effects of ECM on the differentiation of marrow stromal cells (MSCs) towards osteoblasts, by using a scaffold composed of Ti fibers seeded with progenitor cells. The results indicated that bone-like ECM synthesized in vitro could enhance the osteoblastic differentiation of MSCs. Castano [17] reported the effects of ECM on the gene expression of bone marrow stromal cells, confirmed that the expression of the osteogenesis related genes promoted the matrix mineralization process, and proposed ECM modification had a profound influence in bone tissue engineering. The increasing knowledge about the role of the ECM for recruitment, proliferation, differentiation of cells and regeneration of tissue is apt to lead to the creation of an artificial ECM coated implants, that may allow a defined adjustment of the required properties to support the healing process [18].

\section{Collagen}

Collagen is considered one of the most useful biomaterials for applications such as tissue scaffolding, since it is hydrophilic, exhibits negligible cytoxicity, has good hemostatic properties, and is readily available and biocompatible [19]. Coating titanium surface with collagen enhanced osteoblast adhesion and proliferation [20,21]. An in vitro study using bone marrow cells also showed that surface coating with type I collagen showed high ALP activity, collagen synthesis, and mineralized matrix formation [22]. A recent study comparing development of the osteoblastic phenotype in human alveolar bonederived cells showed that a type I collagen coated Ti surface favors cell growth during the proliferative phase and osteoblastic differentiation, as demonstrated by changes in mRNA expression profile during the matrix mineralization phase. These results suggested that collagen involved surface modification may affect the processes of bone healing and remodeling [23].

The reasons why type I collagen have been considered for implant surface coating is because of its high dimensional stability, and its presence in all hard and soft tissues, which make it an essential component for ECM development. Bone is a composite of an organic collagen matrix, among which type 1 collagen largely produced by osteoblasts is the most abundant, and inorganic calcium phosphate. Hence, type 1 collagen was considered to be a biomimetic agent for implant surface coating. Meanwhile, researchers theorized that a collagen-calcium phosphate composite coating mimicking the unique nano-composite structure of native bone tissue, could offer an added value over coatings consisting of merely organic or inorganic components [24,25]. Uezono et al. [26] investigated hydroxyapatite/collagen nanocomposite-coated Ti rod for achieving rapid osseointegration onto bone surface. Their histomorphometric analyses revealed that the hydroxyapatite/collagen group had the greatest bone contact ratio among all candidates. Furthermore, the results from bonding strength tests indicated that the hydroxyapatite/collagen group exhibited the greatest bonding strength to bone. Thus, hydroxyapatite/collagen-coated rods were considered as one of the best candidate materials for achieving rapid osseointegration onto a bone surface.

Nanoscale calcium phosphate and collagen-calcium phosphate composite coatings were used by de Jonge et al. [27] in an effort to improve the anchoring and long-term behavior of Ti implant materials. The biological properties of the coatings were characterized by in vitro cell culture. According to their findings, improvements in both osteoblast differentiation and mineral deposition were most prominent when collagen was co-deposited with calcium phosphate. Osteogenic effects were also displayed for coatings with thicknesses well below 100 $\mathrm{nm}$. What is more, Zhang F et al. [28] exploited potential methods of surface modification for improving the seal between the neck portion of a dental implant and the surrounding soft tissue. In contrast to two control surfaces (one machined, one machined and acid-etched), collagen/hyaluronic acid treatment of $\mathrm{Ti}$ improved the attachment, spreading, proliferation, and differentiation of human gingival fibroblasts.

\section{Growth factor}

Cytokines are polypeptide protein factors of low molecular weight $(<80 \mathrm{KDa})$, that are produced in most nucleated cells of the organism. Hence, its targets are multiple, and different effects are produced that frequently interact with each other [29]. The cytokine group includes growth factors, a heterogeneous family of proteins involved in a wide variety of biological processes related to the proliferation, differentiation, and chemotactism of cells.

In order to improve bone formation around implants, researches have also attempted to use growth factors to target both cellular proliferation and differentiation. Bone morphogenetic proteins (BMPs), transforming growth factor- $\beta 1$ (TGF- $\beta 1$ ), platelet-derived growth factor (PDGF), insulin-like growth factor (IGF)-1 and -2, and fibroblast growth factor-fibronectin (FGF-FN) fusion protein are the most promising candidates for Ti based surface coatings to locally enhance the bone healing process [30].

BMPs: BMP is the generic name of a family of proteins, originally identified in extracts of demineralized bone, that are capable of inducing bone formation at ectopic sites. To date, 20 types and subtypes of BMPs have been reported. All BMPs belong to the TGF- $\beta$ superfamily, except for BMP-1, which is classified as a metalloproteinase. Because of the 
excellent biological properties revealed by experimental studies, BMP-2 and BMP-7 are the most widely studied types.

Coating or immobilizing BMP-2 onto organic or inorganic surfaces is reported to enhance the osseointegration of materials $[31,32]$. Moreover, various methods have been used to incorporate BMPs into dental implants [33-35]. Ti alloy implants bearing a fine, dense, amorphous layer of calcium phosphate were immersed in a supersaturated solution of calcium phosphate containing growth factors such as BMP-2 for $48 \mathrm{~h}$ under physiological conditions of temperature $\left(37^{\circ} \mathrm{C}\right)$ and $\mathrm{pH}(7.4)$. The implants became coated with a crystalline latticework of the inorganic components into which BMP-2 was incorporated. Although BMP-2 itself is osteoinductive, its osteogenic potency was markedly enhanced after incorporation into biomimetic calcium phosphate coatings. Jeonghwa et al. [36] attempted to immobilize BMPs on dopamine-treated $\mathrm{Ti}$ surfaces to enhance osseointegration, and thought the immobilized BMP-2 specifically interacted with myoblasts and induces osteogenic differentiation. Therefore, they proposed that their method was convenient for covalently immobilizing BMP2 while retaining its biological activity.

However, it should be noticed that the success of such functionalization seemed to be strongly dependent on type, delivery and concentration of the coating. When evaluating implant surfaces modified by BMP coatings, some studies have shown confusing results. We know that BMPs, a class of growth factors, can promote bone formation, but they also stimulate the action of osteoclasts. Liu et al. [37] evaluated the influence of BMP-2 and its mode of delivery on the osteoconductivity of dental implants with either a naked Ti surface or a calcium-phosphate-coated one. After 3 weeks, the volume of bone deposited within the osteoconductive space (peri-implant) was highest for coated and uncoated implants bearing no BMP-2, while the lowest value was achieved with coated implants bearing only adsorbed BMP2. It was concluded that the osteoconductivity of implant surfaces can be significantly modulated by BMP-2 and its mode of delivery. In a different dog model, Wikesjö et al. [34] examined the ability of recombinant human BMP-2 (rhBMP-2) coated onto a Ti porous oxide implant surface to stimulate local bone formation, including osseointegration and vertical augmentation of the alveolar ridge. It was concluded that rhBMP-2 coating onto Ti porous oxide implant surfaces induced clinically relevant local bone formation including vertical augmentation of the alveolar ridge and osseointegration. But higher concentrations/doses were associated with negative effects. In summary, further experimental research is required before a BMPenriched implant becomes commercially available [29].

non-BMP growth factors: Non-BMP growth factors have also been tested as potential agents to improve the osseointegration parameters. Recombinant human transforming growth factor-beta 1 (rhTGF- $\beta 1$ ) has recently been shown to be a potent stimulator of bone healing and bone formation in various models in vivo. In a dog model study, TGF- $\beta 1$ was applied to implants to evaluate its influence on bone formation around implants. The results showed that rhTGF- $\beta 1$ adsorbed on tricalcium phosphate-ceramic-coated implants can enhance bone ongrowth by 59\% [38]. Another study confirmed an earlier study in dogs that found a 3-fold increase in the amount of bone ingrowth when the implants were treated with a combination of HA and tricalcium phosphate with TGF- $\beta 1$ [39]. Park et al. [40] evaluated the osseointegration of anodized Ti implants coated with fibroblast growth factor-fibronectin (FGF-FN) fusion protein that were placed in rabbit tibiae. The removal torque values as well as the percentages of BIC of the test group were better than those found for the implants that were not biofunctionalized. Park et al. [40] also evaluated the effects of a tetra-cell adhesion molecule (T-CAM) coating on Ti implants by evaluating bone healing in a rabbit model. After 8 weeks of healing, implants coated with cell adhesion molecules showed more active bone formation and greater amount of mineralized bone tissue in the apical region when compared with uncoated blasted controls.

\section{Polypeptide}

To biofunctionalize implant surfaces, proteins are attractive due to their inherent bioactivity. However, their application may be limited due to the lack of stability and immunogenicity. Furthermore, animal extracted proteins carry the risks of pathogen transmission and variability [41]. Short peptide sequences, which only contain a cellbinding sequence, may be an alternative approach. These small peptides can be produced synthetically and are easily purified, making them cost efficient compared to large proteins. Their activity is independent of their tertiary structure and they are easy to store and sterilize [42].

Among the bioactive substances used, the peptide RGD has been extensively employed to biologically functionalize Ti based implant surfaces [43]. It is well known that the RGD motif is related to cell adhesion, and many biomolecules present this motif. This sequence has a high affinity for some proteins of the integrin family and is of great importance in the binding of cells to the ECM. Previous reports have shown that the introduction of RGD sequences could promote the cell attachment and differentiation of osteogenic cells on Ti based surfaces. Moreover, bone formation could even be accelerated by immobilizing RGD on the Ti based implant surface [44]. In a dog model, Schliephake et al. [45] compared implants with machined Ti surface, coated with collagen I, coated with collagen I and low RGD concentrations (100 $\mu \mathrm{mol} / \mathrm{mL}$ ), and coated with collagen I and high RGD concentrations $(1000 \mu \mathrm{mol} / \mathrm{mL})$. After 1 month, bone-implant contact (BIC) was significantly enhanced only in the group of implants coated with the higher concentration of RGD peptides. Volume density of the newly formed peri-implant bone was significantly higher in all implants with organic coating. No significant difference was found between collagen coating and RGD coatings. After 3 months, BIC was significantly higher in all implants with organic coating than in implants with machined surfaces. The volume density of the newly formed periimplant bone was significantly increased in all coated implants in comparison to machined surfaces. It was concluded that organic coating of machined screw implant surfaces providing binding sites for integrin receptors can enhance bone implant contact and periimplant bone formation. In addition, Germanier et al. [46] compared RGD peptide polymer modified implant surfaces with sandblasted and acid-etched implant surfaces placed in the maxillae of miniature pigs, and confirmed that the functionalization may promote enhanced bone apposition during the early stages of bone regeneration. Despite these highly positive results, another in vivo study found that the presence of the RGD sequence did not improve the adhesion on Ti. The results demonstrate that the RGD sequence is not necessarily required to enhance the adhesion of cells to non-biological surfaces. Moreover, it is shown that the number of adhering cells can be increased by changes in the peptide hydrophobicity. Changes in the cytoskeleton are observed depending on the type of RGD-peptide modification [47]. These findings were in line with Schliephake et al. [48], who investigated the effect of RGD peptide coating of Ti implants on periimplant bone formation in the alveolar crest in an experimental pilot study in dogs. The results provided only weak evidence that coating of Ti implants with RGD peptides in the present form and dosage may increase periimplant bone formation in the alveolar process.

The bone formation could be accelerated by immobilizing RGD on the Ti-based implant surface. However, the physically adsorbed RGD peptide is unstable on $\mathrm{Ti}$ in physiological conditions. Numerous 
methods have been developed so far to introduce RGD peptides onto the surface of biomaterials, including physical adhesion, chemical binding using spacer reagents with biofunctional terminal groups and electrochemical deposition. Huang et al. [43] have developed a new method to fabricate disulfide-crosslinked RGD-containing collagen/ hyaluronic acid polyelectrolyte membrane (PEM) coatings onto Ti via the layer-by-layer (LBL) technique. Such disulfide-crosslinked bioactive coatings with a semi-interpenetrating network (semi-IPN) structure can be further optimized by integrating other peptides, growth factors or drugs into the semi-IPN architecture, such as bFGF ${ }^{49}$ and rhBMP-2 (Figure 3) [50]. The strategy may be important, as controlling either molecular or cell responses at biomaterial-tissue interfaces.

Except for RGD peptide, Lutz and colleagues studied the biofunctionalization of $\mathrm{Ti}$ implants with a biomimetic active peptide (P-15) promoting early osseointegration, and concluded that biofunctionalization of the implant surface with a biomimetic active peptide leads to significantly increased BIC rates at 14 and 30 days and higher peri-implant bone density at 30 days [51].

\section{DNA}

At present, the studies of the surface modification by DNA are relatively limited. In some way, DNA molecules show the distinctive advantages, due to good biocompatibility and special structure and composition [52,53]. As an alternative of using proteins or peptides, DNA molecules have also been incorporated into implant coatings. It is known that DNA molecules can translocate into the cell nucleus to express sequence specific mRNAs which can produce proteins over the course of one to two weeks [54]. Van den Beucken et al. [55] described the effect of multilayered DNA coatings on the formation of mineralized depositions from simulated body fluids (SBF), and osteoblast-like cell behaviors with and without pretreatment in SBF. DNA coatings were generated using electrostatic self-assembly, with poly-d-lysine or poly (allylamine hydrochloride) as cationic polyelectrolytes, on Ti substrates. The results of this study were indicative of the bone-bonding capacities of DNA coatings. Nevertheless, future animal experiments are required to provide conclusive evidence for the bioactivity of DNA coatings.

\section{Conclusion}

Ti based implants were widely used in the oral clinical treatment, strategies and approaches to modify Ti based implant surfaces have always attracted the interests of researchers. Among these explorations, the most promising and anticipated strategy for enhancement of osseointegration at the bone-to-implant interface is the immobilization of biomolecules on Ti surface. Although considerable progress has been made, several technological or clinical problems are still urgent to be resolved, such as harmless introduction of bioactive molecules into Ti surfaces, controlled release profiles of osteogenic reagents at the implantation site, stability of the bioactive coatings, and the effects of the coating on the long-term osseointegration. With constant advancing of scientific research, more and more strategies and methods will be exploited to construct bioactive Ti surfaces, which may show exciting and excellent results in clinic in the future.
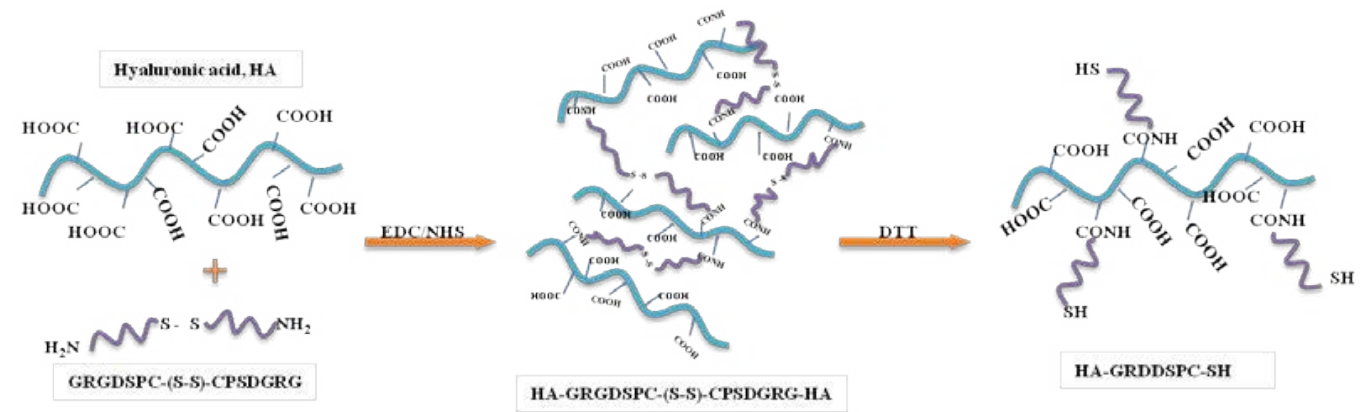

A
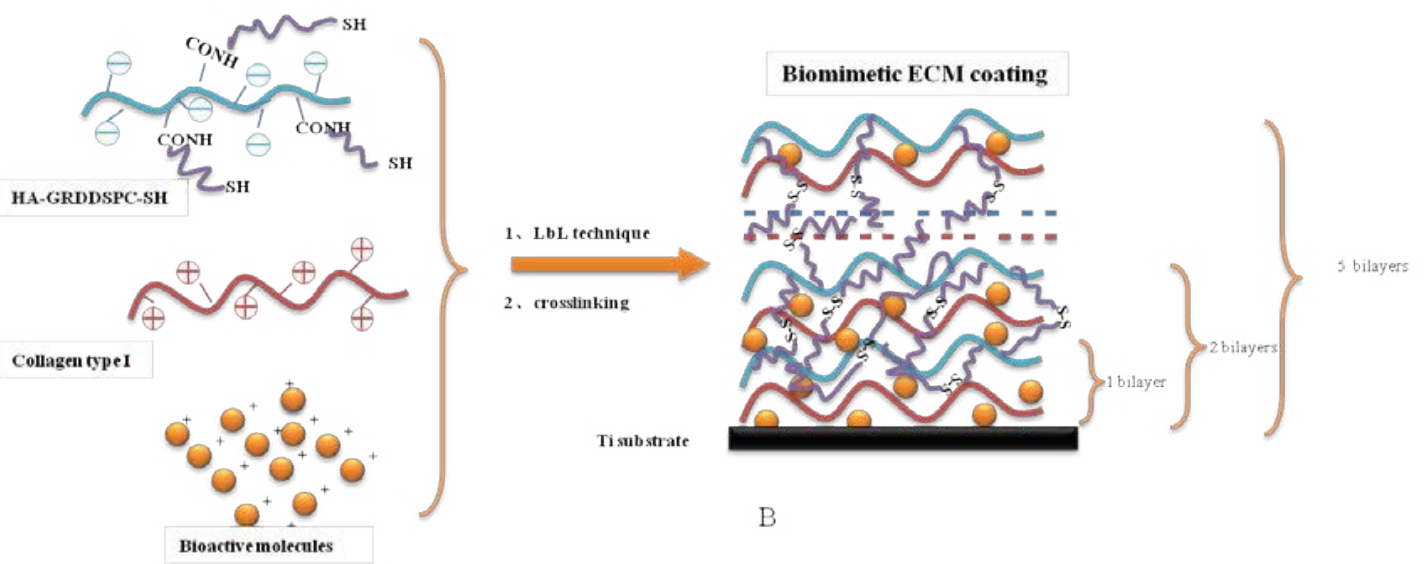

Figure 2: Bioactive signals found within the extracellular environment in bone. 


\section{Acknowledgements}

We are grateful for the financial supports from the National Natural Science Foundation of China (51173163), the National Science-technology Support Plan project of China (2012BAI07B01) and the fundamental Research Funds for the Central Universities (2012QNA7043).

\section{References}

1. Branemark PI, Adell R, Breine U, Hansson BO, Lindstrom J, et al. (1969) Intraosseous anchorage of dental prostheses. I. Experimental studies. Scand $J$ Plast Reconstr Surg 3: 81-100.

2. Misch CE, Perel ML, Wang HL, Sammartino G, Galindo-Moreno P, et al. (2008) Implant success, survival, and failure: the International Congress of Oral Implantologists (ICOI) Pisa Consensus Conference. Implant Dent 17: 5-15.

3. Chua PH, Neoh KG, Kang ET, Wang W (2008) Surface functionalization of titanium with hyaluronic acid/chitosan polyelectrolyte multilayers and RGD for promoting osteoblast functions and inhibiting bacterial adhesion. Biomaterials 29: 1412-1421.

4. Ito $Y$, Kajihara M, Imanishi $Y$ (1991) Materials for enhancing cell adhesion by immobilization of cell-adhesive peptide. J Biomed Mater Res 25: 1325-1337.

5. Schatz F, Papp C, Aigner S, Krikun G, Hausknecht V, et al. (1997) Biological mechanisms underlying the clinical effects of RU 486: modulation of cultured endometrial stromal cell stromelysin-1 and prolactin expression. J Clin Endocrinol Metab 82: 188-193.

6. Krupa D, Baszkiewicz J, Kozubowski JA, Mizera J, Barcz A, et al. (2015) Corrosion resistance and bioactivity of titanium after surface treatment by three different methods: ion implantation, alkaline treatment and anodic oxidation. Anal Bioanal Chem 381: 617-625.

7. Borsari V, Fini M, Giavaresi G, Tschon M, Chiesa R, et al. (2009) Comparative in vivo evaluation of porous and dense duplex titanium and hydroxyapatite coating with high roughnesses in different implantation environments. J Biomed Mater Res A 89: 550-560.

8. Rupp F, Scheideler L, Olshanska N, de Wild M, Wieland M, et al. (2006) Enhancing surface free energy and hydrophilicity through chemical modification of microstructured titanium implant surfaces. J Biomed Mater Res A 76: 323-334.

9. Huang Y, Zha G, Luo Q, Zhang J, Zhang F, et al. (2014) The construction of hierarchical structure on $\mathrm{Ti}$ substrate with superior osteogenic activity and intrinsic antibacterial capability. Sci Rep 4: 6172.

10. Beutner R, Michael J, Schwenzer B, Scharnweber D (2010) Biological nanofunctionalization of titanium-based biomaterial surfaces: a flexible toolbox. J R Soc Interface 7 Suppl 1: S93-93S105.

11. Guarnieri D, De Capua A, Ventre M, Borzacchiello A, Pedone C, et al. (2010) Covalently immobilized RGD gradient on PEG hydrogel scaffold influences cell migration parameters. Acta Biomater 6: 2532-2539.

12. Liu Y, de Groot K, Hunziker EB (2004) Osteoinductive implants: the mise-enscÃ"ne for drug-bearing biomimetic coatings. Ann Biomed Eng 32: 398-406.

13. Shekaran A, Garcia AJ (2011) Extracellular matrix-mimetic adhesive biomaterials for bone repair. J Biomed Mater Res A 96: 261-272.

14. de Jonge LT, Leeuwenburgh SC, Wolke JG, Jansen JA (2008) Organicinorganic surface modifications for titanium implant surfaces. Pharm Res 25: 2357-2369.

15. Rammelt S, Heck C, Bernhardt R, Bierbaum S, Scharnweber D, et al. (2007) In vivo effects of coating loaded and unloaded $\mathrm{Ti}$ implants with collagen, chondroitin sulfate, and hydroxyapatite in the sheep tibia. J Orthop Res 25: 1052-1061.

16. Datta N, Holtorf HL, Sikavitsas VI, Jansen JA, Mikos AG (2005) Effect of bone extracellular matrix synthesized in vitro on the osteoblastic differentiation of marrow stromal cells. Biomaterials 26: 971-977.

17. Castano-Izquierdo $\mathrm{H}$, Alvarez-Barreto J, van den Dolder J, Jansen JA, Mikos AG, (2007) Pre-culture period of mesenchymal stem cells in osteogenic media influences their in vivo bone forming potential. J Biomed Mater Res A 82: 129-138.

18. Zhao H, Li Q, Wang Q, Wang Z (2013) [Research progress in surface modification of orthopaedic implants via extracellular matrix components]. Zhongguo Xiu Fu Chong Jian Wai Ke Za Zhi 27: 1390-1394.

19. Stylianou A, Yova D, Politopoulos K (2012) Atomic Force Microscopy Surface Nanocharacterization of UV-Irradiated Collagen Thin Films, leee 12th International Conference on Bioinformatics \& Bioengineering 603-608.
20. Geissler U, Hempel U, Wolf C, Scharnweber D, Worch H, et al. (2000) Collagen type I-coating of Ti6Al4V promotes adhesion of osteoblasts. J Biomed Mater Res 51: 752-760.

21. Li X, Luo Q, Huang Y, Li X, Zhang F, et al. (2012) The responses of preosteoblasts to collagen/hyaluronic acid polyelectrolyte multilayer coating on titanium. Polym Adv Technol 23: 756-764.

22. Mizuno M, Imai T, Fujisawa R, Tani H, Kuboki Y (2000) Bone sialoprotein (BSP) is a crucial factor for the expression of osteoblastic phenotypes of bone marrow cells cultured on type I collagen matrix. Calcif Tissue Int 66: 388-396.

23. de Assis AF, Beloti MM, Crippa GE, de Oliveira PT, Morra M, et al. (2009) Development of the osteoblastic phenotype in human alveolar bone-derived cells grown on a collagen type I-coated titanium surface. Clin Oral Implants Res 20: 240-246.

24. Otsuka M, Nakagawa H, Ito A, Higuchi WI (2010) Effect of geometrical structure on drug release rate of a three-dimensionally perforated porous apatite/ collagen composite cement. J Pharm Sci 99: 286-292.

25. Wahl DA, Czernuszka JT (2006) Collagen-hydroxyapatite composites for hard tissue repair. Eur Cell Mater 11: 43-56.

26. Uezono M, Takakuda K, Kikuchi M, Suzuki S, Moriyama K (2013) Hydroxyapatite/collagen nanocomposite-coated titanium rod for achieving rapid osseointegration onto bone surface. J Biomed Mater Res B 101B: 1031-1038.

27. de Jonge LT, Leeuwenburgh SC, van den Beucken JJ, te Riet J, Daamen WF, et al. (2010) The osteogenic effect of electrosprayed nanoscale collagen/ calcium phosphate coatings on titanium. Biomaterials 31: 2461-2469.

28. Zhang F, Huang Y, Li X, Zhao S (2011) Surface modification and its effect on attachment, spreading, and proliferation of human gingival fibroblasts. Int $J$ Oral Maxillofac Implants 26: 1183-1192.

29. Avila G, Misch K, Galindo-Moreno P, Wang HL (2009) Implant surface treatment using biomimetic agents. Implant Dent 18: 17-26.

30. Park JM, Koak JY, Jang JH, Han CH, Kim SK, et al. (2006) Osseointegration of anodized titanium implants coated with fibroblast growth factor-fibronectin (FGF-FN) fusion protein. Int J Oral Maxillofac Implants 21: 859-866.

31. Schuessele A, Mayr H, Tessmar J, Goepferich A (2009) Enhanced bone morphogenetic protein-2 performance on hydroxyapatite ceramic surfaces. J Biomed Mater Res A 90: 959-971.

32. Kloss FR, Gassner R, Preiner J, Ebner A, Larsson K, et al. (2008) The role of oxygen termination of nanocrystalline diamond on immobilisation of BMP-2 and subsequent bone formation. Biomaterials 29: 2433-2442.

33. Tatakis DN, Koh A, Jin L, Wozney JM, Rohrer MD, et al. (2002) Peri-implant bone regeneration using recombinant human bone morphogenetic protein-2 in a canine model: a dose-response study. J Periodontal Res 37: 93-100.

34. Wikesjo UM, Qahash M, Polimeni G, Susin C, Shanaman RH, et al. (2008) Alveolar ridge augmentation using implants coated with recombinant human bone morphogenetic protein-2: histologic observations. J Clin Periodontol 35 1001-1010.

35. Wikesjo UM, Huang YH, Xiropaidis AV, Sorensen RG, Rohrer MD, et al (2008) Bone formation at recombinant human bone morphogenetic protein-2coated titanium implants in the posterior maxilla (Type IV bone) in non-human primates. J Clin Periodontol 35: 992-1000.

36. Kang J, Tada S, Kitajima T, Son TI, Aigaki T, et al. (2013) Immobilization of bone morphogenetic protein on DOPA- or dopamine-treated titanium surfaces to enhance osseointegration. Biomed Res Int 2013: 265980.

37. Liu Y, Enggist L, Kuffer AF, Buser D, Hunziker EB (2007) The influence of BMP2 and its mode of delivery on the osteoconductivity of implant surfaces during the early phase of osseointegration. Biomaterials 28: 2677-2686.

38. Lind M, Overgaard S, Ongipattanakul B, Nguyen T, Bunger C, et al. (1996) Transforming growth factor-beta 1 stimulates bone ongrowth to weight-loaded tricalcium phosphate coated implants - An experimental study in dogs. J Bone Joint Surg Br 78B: 377-382.

39. Sumner DR, Turner TM, Purchio AF, Gombotz WR, Urban RM, et al. (1995) Enhancement of bone ingrowth by transforming growth factor-beta. $J$ Bone Joint Surg Am 77: 1135-1147.

40. Park JW, Lee SG, Choi BJ, Suh JY (2007) Effects of a cell adhesion molecule coating on the blasted surface of titanium implants on bone healing in the rabbit femur. Int J Oral Maxillofac Implants 22: 533-541.

41. Liu W, Merrett K, Griffith M, Fagerholm P, Dravida S, et al. (2008) Recombinant 
human collagen for tissue engineered corneal substitutes. Biomaterials 29 : $1147-1158$

42. Dettin M, Conconi MT, Gambaretto R, Bagno A, Di Bello C, et al. (2005) Effect of synthetic peptides on osteoblast adhesion. Biomaterials 26: 4507-4515.

43. Huang Y, Luo Q, Li X, Zhang F, Zhao S (2012) Fabrication and in vitro evaluation of the collagen/hyaluronic acid PEM coating crosslinked with functionalized RGD peptide on titanium. Acta Biomater 8: 866-877.

44. Roessler S, Born R, Scharnweber D, Worch H, Sewing A, et al. (2001) Biomimetic coatings functionalized with adhesion peptides for dental implants. J Mater Sci Mater Med 12: 871-877.

45. Schliephake H, Scharnweber D, Dard M, Sewing A, Aref A, et al. (2005) Functionalization of dental implant surfaces using adhesion molecules. J Biomed Mater Res B Appl Biomater 73: 88-96.

46. Germanier Y, Tosatti S, Broggini N, Textor M, Buser D (2006) Enhanced bone apposition around biofunctionalized sandblasted and acid-etched titanium implant surfaces. A histomorphometric study in miniature pigs. Clin Oral Implants Res 17: 251-257.

47. Senyah N, Hildebrand G, Liefeith K (2005) Comparison between RGD-peptidemodified titanium and borosilicate surfaces. Anal Bioanal Chem 383: 758-762.

48. Schliephake H, Scharnweber D, Dard M, Rossler S, Sewing A, et al. (2002) Effect of RGD peptide coating of titanium implants on periimplant bone formation in the alveolar crest. An experimental pilot study in dogs. Clin Oral Implants Res 13: 312-319.
49. Luo Q, Huang Y, Deng X, Zhang J, Li X, et al. (2013) Polyelectrolyte multilayer coating with two regulatory molecules on titanium: construction and its biological effects. Nanomedicine (Lond) 8: 739-755.

50. Huang Y, Luo Q, Zha G, Zhang J, Li X, et al. (2014) Biomimetic ECM coatings for controlled release of rhBMP-2: construction and biological evaluation. Biomaterials Science 2: 980-989.

51. Lutz R, Srour S, Nonhoff J, Weisel T, Damien CJ, et al. (2010) Biofunctionalization of titanium implants with a biomimetic active peptide $(\mathrm{P}-15)$ promotes early osseointegration. Clin Oral Implants Res 21: 726-734.

52. Dhore CR, Snel SJ, Jacques SV, Naert IE, Walboomers XF, et al. (2008) In vitro osteogenic potential of bone debris resulting from placement of titanium screwtype implants. Clin Oral Implants Res 19: 606-611.

53. van den Beucken JJ, Walboomers XF, Vos MR, Sommerdijk NA, Nolte RJ, et al. (2007) Biological responses to multilayered DNA-coatings. J Biomed Mater Res B Appl Biomater 81: 231-238.

54. Dupont KM, Boerckel JD, Stevens HY, Diab T, Kolambkar YM, et al. (2012) Synthetic scaffold coating with adeno-associated virus encoding BMP2 to promote endogenous bone repair. Cell Tissue Res 347: 575-588.

55. van den Beucken JJ, Walboomers XF, Leeuwenburgh SC, Vos MR, Sommerdijk NA, et al. (2007) Multilayered DNA coatings: in vitro bioactivity studies and effects on osteoblast-like cell behavior. Acta Biomater 3: 587-596. 